Annals of International Medical and Dental Research

E-ISSN: 2395-2822 | P-ISSN: 2395-2814

Vol-8, Issue-1 | January-February 2022

DOI: $10.53339 /$ aimdr.2022.8.1.42

Page no- 333-340 | Section- Research Article (Neuro Surgery)

\title{
An Observational Study on Idiopathic Intracranial Hypertension (IIH) in a Tertiary Care Hospital in Bangladesh
}

\author{
Md. Rashidoon Nabi Khan ${ }^{1 *}$
}

\begin{abstract}
${ }^{1}$ Associate Professor, Department of Neuro Surgery, Sylhet, MAG Osmani Medical College and Hospital, Sylhet, Bangladesh.

Email: mdrnabikhan@gmail.com

Orcid ID: 0000-0003-1039-7446

*Corresponding author
\end{abstract}

Received: 28 August 2021

Revised: 14 November 2021

Accepted: 23 November 2021

Published: 22 December 2021

\begin{abstract}
Background: Among the risk factors of cardiovascular diseases, hypertension is one of the major reason. Intracranial hypertension (IIH) is a pressure buildup around the brain. It can happen unexpectedly, as a result of a severe head injury, stroke, or brain abscess could be occurred. It could also be a chronic, long-term condition, known as IIH. It results in the signs and symptoms of a brain tumor. Which is also known as benign intracranial hypertension. Cerebrospinal fluid, or CSF, is the fluid that surrounds the spinal cord and brain. CSF can accumulate if too much fluid is produced or not enough is reabsorbed. This can induce symptoms similar to a brain tumor. Intracranial Hypertension can be classified into three categories, they are Acute, Chronic and Idiopathic. IIH is recognized when the increased intracranial pressure cannot be explained by any other underlying cause. Aim: The aim of the study was to observe idiopathic intracranial hypertension patients in a select tertiary care hospital of Bangladesh. Methods: This cross-sectional observational study was conducted at the Department of Neurosurgery, Sylhet M. A. G. Osmani Medical College Hospital, Sylhet, Bangladesh. The study duration was from January 2012 to December 2020. A total number of 47 participants had been recruited as study population. Results: Male: female ratio was 1:10.75, and $91 \%$ of the total participants were female. $40.43 \%$ of the participants were aged between $21-30$ years. $46.81 \%$ were overweight and $34.04 \%$ were obese. Most common symptom was nausea, followed by visual impairment and double vision. Conclusion: The prevalence of Idiopathic Intracranial Hypertension is much higher among the female. Female and high BMI are significant risk factors of IIH. It is more prevalent among young adults, and results on various vision related symptoms.
\end{abstract}

Keywords:- Intracranial, Hypertension, Vision, BMI

\section{INTRODUCTION}

Cardiovascular disease is one of the leading cause of deaths worldwide. It is responsible for $1 / 3$ of total global deaths. [1] There are various risk factors associated with cardiovascular diseases, both modifiable and non-modifiable types. Clinical investigations have shown that when modifiable risk factors are addressed and rectified, the likelihood of developing cardiovascular disease (CVD) is decreased.[2] Research has also concluded that risk factors of cardiovascular diseases are multifactorial in 
Annals of International Medical and Dental Research

E-ISSN: 2395-2822 | P-ISSN: 2395-2814

Vol-8, Issue-1 | January-February 2022

DOI: $10.53339 /$ aimdr.2022.8.1.42

Page no- 333-340 | Section- Research Article (Neuro Surgery)

nature, and interact over time to produce CVD. Recent studies suggest that the number of people at high risk of CVD are continuously increasing, and at present, all except $2-7 \%$ of the population has some form of risk factors of cardiovascular diseases. [3] Some of the modifiable risk factors of CVD are smoking, hypertension, high-blood pressure, cholesterol levels and body weight. Among these risk factors, the present study aimed to focus on a specific type of hypertension, named as Idiopathic Intracranial hypertension, or IIH. Hypertension, otherwise known as high blood pressure, is a condition where the blood vessels have a continuously raised blood pressure. Intracranial hypertension is the buildup of cerebral or spinal fluids around the head, neck or the base of the skull. It can be caused by various causes like blood clot on the surface of the brain, brain tumor, infection etc. [4] In cases where the cause of the intracranial hypertension (IH) is unknown or unclear, that is dubbed as idiopathic intracranial hypertension (IIH), or benign intracranial hypertension. [5] The main symptoms of IIH includes headache, vision problems, shoulder pain, ringing in the ears and in some cases, vision loss. $[6,7]$ The most common symptom of IIH is headache, which occurs in the vast majority of the cases. The headache can worsen by activities like coughing or sneezing, which increases the intracranial pressure above normal. IIH can only be diagnosed when the presenting symptoms cannot be explained by any other symptoms. By definition, IIH has no definite causes, but some medications like high dose vitamin-A derivatives, hormonal contraceptives and use of tetracycline antibiotics have been observed to increase the intracranial pressure. [8] Although use of Oral Contraceptive Pill (OCP) was considered as a risk factor for IIH some recent studies have proven that no significant association was found between OCP use and IIH. $[9,10]$ Some rare diseases can also lead to an increased intracranial pressure, but in such cases where the intracranial pressure is the underlying cause of another disease, the condition is termed as secondary intracranial hypertension. [11] Although the exact cause of IIH is still not known, there are multiple theories linked to the diseases. The original theory was that the increased production of cerebrospinal fluid in the body, and the second theory is that an increased blood flow to the brain or an overall increase of the brain tissue is the underlying cause of IIH. But very few research is available to support either of the theories. Another theory proposes that congested venous drainage from the brain is caused by limited venous drainage, as many patients with IIH have transverse sinus narrowing. [12] The diagnosis of IIH can be a suspected result of history and examination, and various tests like CT, CAT or MRI can be conducted to confirm the diagnosis. More tests and examinations might be performed if the history of symptoms is not typical, or there are high possibilities of alternative ailments. [13]

\section{Objective}

\section{General Objective}

To observe the status of Idiopathic Intracranial Hypertension patients of a select tertiary care hospital

\section{Specific Objectives}

- To observe and evaluate risk factors of Idiopathic Intracranial Hypertension patients in a tertiary care hospital

- To observe and evaluate possible associated factors of Idiopathic Intracranial 
Annals of International Medical and Dental Research

E-ISSN: 2395-2822 | P-ISSN: 2395-2814

Vol-8, Issue-1 | January-February 2022

DOI: $10.53339 /$ aimdr.2022.8.1.42

Page no- 333-340 | Section- Research Article (Neuro Surgery)

Hypertension patients in a tertiary care hospital

\section{MATERIAL AND METHODS}

This cross-sectional observational study was conducted at the Department of Neurosurgery, Sylhet M. A. G. Osmani Medical College, Sylhet, Bangladesh. The study was conducted over an 8 year duration, from January 2012 to December 2020. The initial sample size was 47 . The participants were selected based on convenient sampling method. Patient history, laboratory findings, medications and follow up data were all recorded in a pre-prepared questionnaire. Lumber drainage was done using spinal tab to determine the pressure of cerebrospinal fluid. The participants were treated with Tab Acetazolamide $250 \mathrm{mg}$ twice a day for 6 weeks. All the participants had a follow up after 3-6 weeks of treatment. Informed written consent was taken from all participants, and ethical approval was obtained from the departments ethical review committee.

\section{Inclusion Criteria}

- Age $>10$ years

- Age $<51$ years

- Patients who had given consent to participate in the study.

- Patients showing IIH symptoms or presentations

\section{Exclusion Criteria}

- Mentally ill.

- Unable to answer the criteria question.

- Age $<10$ years

- Negative CT, MRI and MRV scans

- Exclude those affected with other chronic diseases etc.

\section{RESULTS}

Male: female ratio was $1: 10.75$, and $91 \%$ of the total participants were female. $40.43 \%$ of the participants were aged between 21-30 years. $46.81 \%$ were overweight and $34.04 \%$ were obese. Most common symptom was nausea, followed by visual impairment and double vision.

[Figure 1] showed, among the participants, 91\% were female, and only $9 \%$ were male. The male: female ratio was 1:10.75.

[Table 1] showed that, among the participants, very few were older than 40 years of age. Only $6.38 \%$ of the participants belonged to the age group of 41-50 years. Majority of the participants were young adults, with $40.43 \%$ from the age group of $21-30$ years, $21.28 \%$ from the age group of $31-40$ years, and $31.91 \%$ from the age group of 11-20 years. The prevalence of participants showed a decrease over age.

According to [Table 2], the majority of the participants $(46.81 \%)$ were overweight (BMI 2529 ), while $34.04 \%$ were obese, and only $19.15 \%$ were of healthy weight.

[Table 3] stated, as IIH is a diagnosis of exclusion, $40.43 \%$ had only gone through CT scan, while $65.96 \%$ had to take both CT and MRI tests to confirm IIH. $27.66 \%$ of the participants had to take CT, MRI and MRV for a successful diagnosis of IIH.

[Table 4] stated, the most frequent symptoms presented among the participants were related to optic capabilities of the participants. Although $97.87 \%$ of the participants had nausea, $87.23 \%$ of the participants had various levels of visual impairments, from mild to 
Annals of International Medical and Dental Research

E-ISSN: 2395-2822 | P-ISSN: 2395-2814

Vol-8, Issue-1 | January-February 2022

DOI: $10.53339 /$ aimdr.2022.8.1.42

Page no- 333-340 | Section- Research Article (Neuro Surgery)

severe. Double vision was present in $80.85 \%$ of the participants, while $6.38 \%$ of the participants had optic atrophy. $51.06 \%$ of the participants had head and neck pains, and $29.79 \%$ of the participants faced tinnitus, or ringing noise in ears.

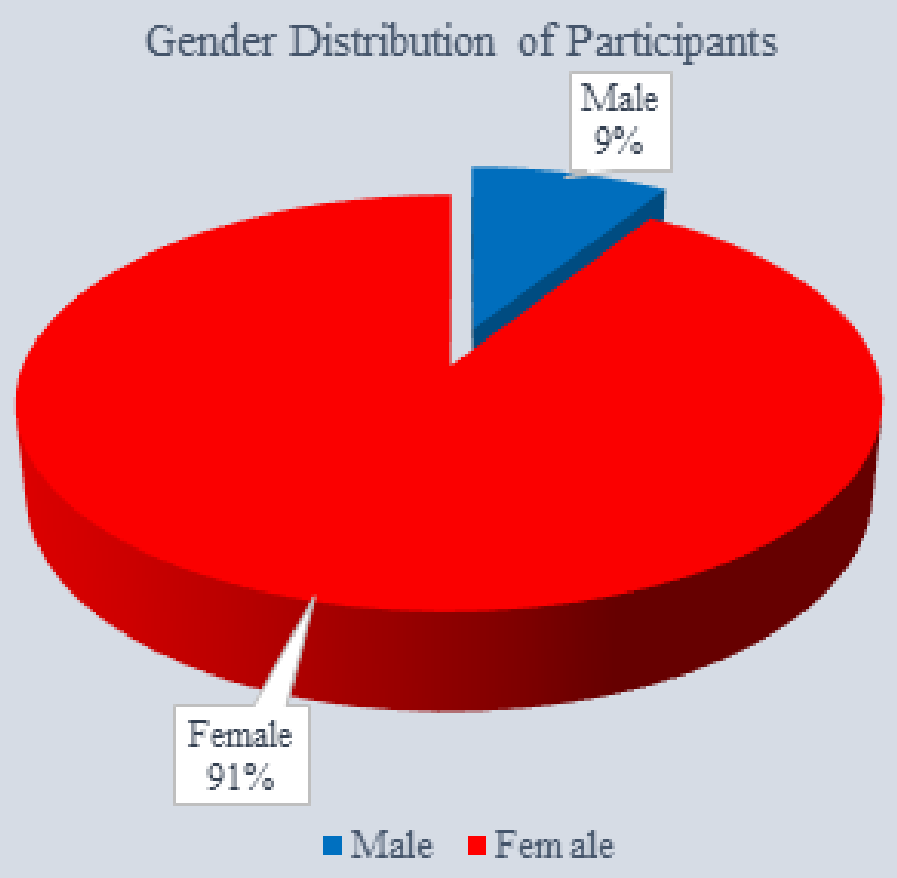

Figure 1: Gender distribution of the participants $(\mathrm{N}=47)$

Table 1: Age distribution of the participants $(\mathrm{N}=47)$

\begin{tabular}{|l|l|l|l|}
\hline Age (in years) & Frequency (n) & Percentage (\%) & P value \\
\hline $11-20$ yrs. & 15 & 31.91 & $0.112 \mathrm{~ns}$ \\
\hline $21-30$ yrs. & 19 & 40.43 \\
\hline $31-40$ yrs. & 10 & 21.28 \\
\hline $41-50$ yrs. & 3 & 6.38 & \\
\cline { 1 - 2 } & &
\end{tabular}

Chi-Square Tests

Table 2: BMI distribution of the participants $(\mathrm{N}=47)$

\begin{tabular}{|l|l|l|l|}
\hline BMI & Frequency (n) & Percentage (\%) & P value \\
\hline Healthy Weight $(<25)$ & 9 & 19.15 & $0.431 \mathrm{~ns}$ \\
\cline { 1 - 3 } Overweight $(25-29)$ & 22 & 46.81 & \\
\cline { 1 - 3 } Obese $(>29)$ & 16 & 34.04 & \\
\hline
\end{tabular}

Table 3: Investigation method distribution of the participants $(\mathrm{N}=47)$ 
Annals of International Medical and Dental Research

E-ISSN: 2395-2822 | P-ISSN: 2395-2814

Vol-8, Issue-1 | January-February 2022

DOI: $10.53339 /$ aimdr.2022.8.1.42

Page no- 333-340 | Section- Research Article (Neuro Surgery)

\begin{tabular}{|l|l|l|l|}
\hline Investigation Procedure & Frequency (n) & Percentage (\%) & P value \\
\hline CT scan o scan o scan onlynly & 19 & 40.43 & $0.001 s$ \\
\cline { 1 - 2 } CT+MRI & 31 & 65.96 & \\
\hline CT+MRI+MRV & 13 & 27.66 & \\
\hline
\end{tabular}

\section{Distribution of Investication Methods}

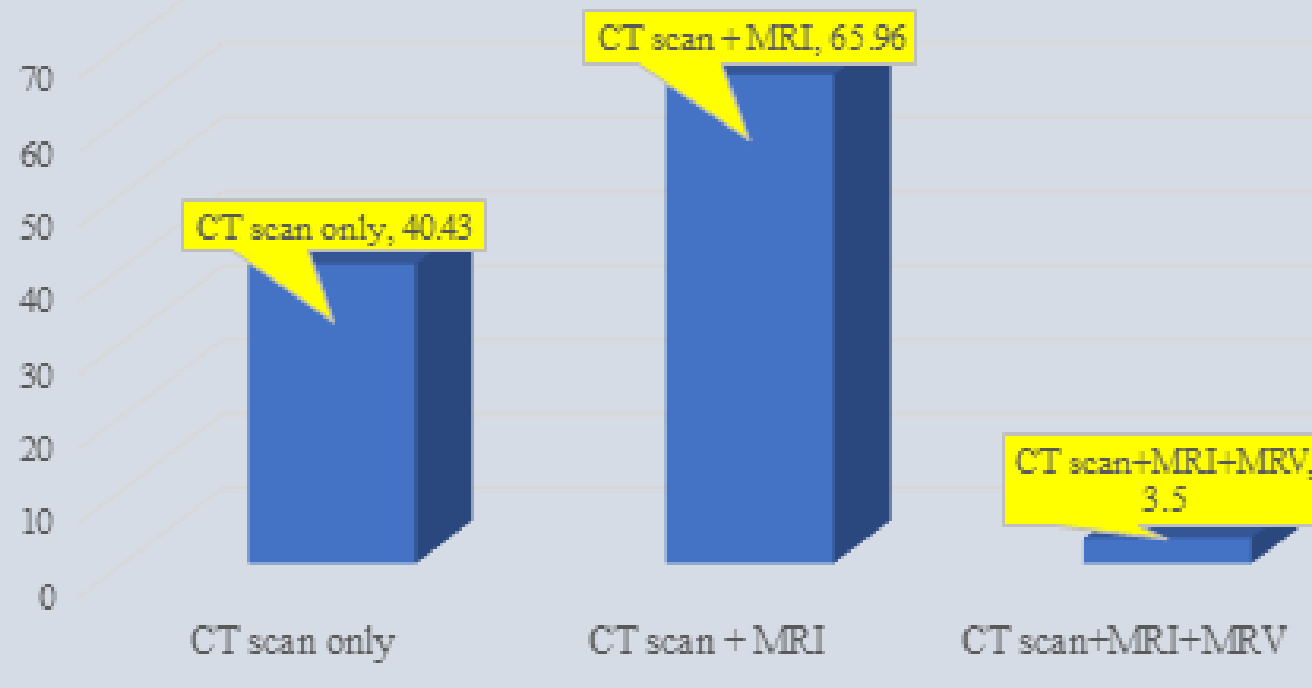

Figure 2: Investigation Distribution of the participants $(\mathrm{N}=47)$

Table 4: Symptom distribution of the participants $(\mathrm{N}=47)$

\begin{tabular}{|l|l|l|l|}
\hline Symptoms & Frequency (n) & Percentage (\%) & P value \\
\hline Nausea & 46 & 97.87 & \multirow{2}{*}{$0.001 \mathrm{~s}$} \\
\cline { 1 - 3 } Visual Impairment (mild to severe) & 41 & 87.23 & \\
\cline { 1 - 3 } Double vision & 38 & 80.85 \\
\hline Head and neck pain & 24 & 51.06 \\
\cline { 1 - 2 } Tinnitus & 14 & 29.79 \\
\cline { 1 - 3 } Optic Atrophy & 3 & 6.38 & \\
\cline { 1 - 2 }
\end{tabular}

\section{DISCUSSION}

IIH affects around one in every 100,000 persons and can affect both children and adults. It is very common in the female population, and being even $10 \%$ overweight might raise the risk of IIH. The German physician Heinrich Quincke reported IIH for the first time in 1893 under the label serous meningitis.14] Following that, several more occurrences were reported in the literature; in many cases, the increased intracranial pressure was caused by underlying 
Annals of International Medical and Dental Research

E-ISSN: 2395-2822 | P-ISSN: 2395-2814

Vol-8, Issue-1 | January-February 2022

DOI: $10.53339 /$ aimdr.2022.8.1.42

Page no- 333-340 | Section- Research Article (Neuro Surgery)

diseases.[15] By the current definition, intracranial hypertension is recognized as idiopathic when no underlying cause can be determined. As it is a diagnosis of exclusion, physicians often prescribe tests like CT, MRI, MRV and others based on the presenting symptoms of the participants. The present study used all of these methods where necessary, along with cerebrospinal fluid pressure measurement, to detect intracranial pressure. In the present study, over $90 \%$ of the participants were female, and only 4 out of the 47 total participants were male. The female sex has been recognized as a major risk factor for IIH through many studies. $[16,17,18]$ In the present study, the incidence of IIH was highest among the adults and young adults, with $40.43 \%$ of the participants belonging to the age group of 21-30 years. The second highest prevalence was observed in the age group of 11-20 years, and the lowest prevalence of $6.58 \%$ was observed in the oldest age group. These findings were similar to another study where the highest and second highest prevalence of IIH participant were observed in age groups 20-29 and 13-19 years respectively. ${ }^{[19]}$ Among the participants of the present study, only $19.15 \%$ were of a healthy BMI, while $46.81 \%$ were overweight and 34.04\% were from the obese category. These findings were supported by many other similar works of literature. $[20,21]$ For the investigation method of the participants, to reach a conclusion of whether the intracranial hypertension was idiopathic in nature or caused by some underlying ailment, CT, MRI and even MRV tests were done where necessary. For $40.43 \%$ of the cases, Only CT scan was performed. $65.96 \%$ of the participants had to take both CT scan and
MRI tests, and $27.66 \%$ of the participants had to go through CT scan, MRI and MRV all together to reach a conclusion on whether they had IIH or not. IIH causes many types of complications, but many studies have found vision problems and vision loss to be present in maximum number of the participants. [22,23] This was reflected in our study as well, where $87.23 \%$ of the participants faced various degrees of visual impairments. Although the most common symptom was nausea, present in $97.87 \%$ of the participants, it can be caused as a result of visual impairment as well, other than due to rise in intracranial pressure. [24] Some other vision related symptoms were double vision, present in $80.85 \%$ of the participants, and optic atrophy, present in $6.38 \%$ of the participants. Other symptoms found in the present study were head and neck pain, and ringing in ears (tinnitus), observed in $51.06 \%$ and $29.79 \%$ of the participants respectively.

\section{Limitations of the study}

The study was conducted in a single hospital with a very small sample size. So, the results may not represent the whole community. Overall financial cost was also a burden for many participants, causing them to drop out of the study, further decreasing the sample size.

\section{CONCLUSIONS}

The prevalence of Idiopathic Intracranial Hypertension (IIH) is much higher among the female. Female and high BMI are significant risk factors of IIH. It is more prevalent among young adults, and results on various vision related symptoms. 
Annals of International Medical and Dental Research

E-ISSN: 2395-2822 | P-ISSN: 2395-2814

Vol-8, Issue-1 | January-February 2022

DOI: 10.53339/aimdr.2022.8.1.42

Page no- 333-340 | Section- Research Article (Neuro Surgery)

\section{REFERENCES}

1. Benjamin EJ, Blaha MJ, Chiuve SE, Cushman M, Das $\mathrm{SR}$, Deo R, et al; American Heart Association Statistics Committee and Stroke Statistics Subcommittee. Heart Disease and Stroke Statistics2017 Update: A Report From the American Heart Association. Circulation. 2017;135(10):e146-e603. doi: 10.1161/CIR.0000000000000485.

2. D'Agostino RB Sr, Pencina MJ, Massaro JM, Coady S. Cardiovascular Disease Risk Assessment: Insights from Framingham. Glob Heart. 2013;8(1):11-23. doi: 10.1016/j.gheart.2013.01.001.

3. Dahlöf B. Cardiovascular disease risk factors: epidemiology and risk assessment. Am J Cardiol. 2010;105(1 Suppl):3A-9A. doi: 10.1016/j.amjcard.2009.10.007.

4. Wall M. Idiopathic intracranial hypertension. Neurol Clin. 2010;28(3):593-617. doi:10.1016/j.ncl.2010.03.003

5. Thurtell MJ. Idiopathic Intracranial Hypertension. Continuum (Minneap Minn). 2019;25(5):1289-1309. doi: 10.1212/CON.0000000000000770.

6. Wall M. Update on Idiopathic Intracranial Hypertension. Neurol Clin. 2017;35(1):45-57. doi:10.1016/j.ncl.2016.08.004

7. Jensen RH, Radojicic A, Yri H. The diagnosis and management of idiopathic intracranial hypertension and the associated headache. Ther Adv Neurol Disord. 2016;9(4):317-326. doi:10.1177/1756285616635987

8. Koch-Weser J, Gilmore EB. Benign intracranial hypertension in an adult after tetracycline therapy. JAMA. 1967;200(4):345-7.

9. Wall M, George D. Idiopathic intracranial hypertension. A prospective study of 50 patients. Brain. 1991;114 ( Pt 1A):155-80.

10. Kilgore KP, Lee MS, Leavitt JA, Frank RD, McClelland CM, Chen JJ. A Population-Based, CaseControl Evaluation of the Association Between Hormonal Contraceptives and Idiopathic Intracranial Hypertension. Am J Ophthalmol. 2019;197:74-79. doi: 10.1016/j.ajo.2018.09.014.

11. Binder DK, Horton JC, Lawton MT, McDermott MW. Idiopathic intracranial hypertension. Neurosurgery. 2004;54(3):538-51; doi: 10.1227/01.neu.0000109042.87246.3c.

12. Farb RI, Vanek I, Scott JN, Mikulis DJ, Willinsky RA, Tomlinson G, et al. Idiopathic intracranial hypertension: the prevalence and morphology of sinovenous stenosis. Neurology. 2003;60(9):1418-24. doi: 10.1212/01.wnl.0000066683.34093.e2.

13. Friedman DI, Jacobson DM. Diagnostic criteria for idiopathic intracranial hypertension. Neurology. 2002;59(10):1492-5. doi: 10.1212/01.wnl.0000029570.69134.1b.

14. Benediktsson G. Meningitis serosa. Laeknabladid. 1957;41(4):54-64.

15. Smith H, Joint C, Schlugman D, Nandi D, Stein JF, Aziz TZ. Motor cortex stimulation for neuropathic pain. Neurosurg Focus. 2001;11(3):E2. doi: 10.3171/foc.2001.11.3.3.

16. Raoof N, Sharrack B, Pepper IM, Hickman SJ. The incidence and prevalence of idiopathic intracranial hypertension in Sheffield, UK. Eur J Neurol. 2011;18(10):1266-8. doi: 10.1111/j.14681331.2011.03372.x.

17. Miah L, Strafford H, Fonferko-Shadrach B, Hollinghurst J, Sawhney IM, Hadjikoutis S, et al. Incidence, Prevalence and Healthcare Outcomes in Idiopathic Intracranial Hypertension: A Population Study. Neurology. 2021;96(8):e1251-61. doi: 10.1212/WNL.0000000000011463.

18. Rowe FJ, Sarkies NJ. The relationship between obesity and idiopathic intracranial hypertension. Int J Obes Relat Metab Disord. 1999;23(1):54-9. doi: 10.1038/sj.ijo.0800758.

19. Adderley NJ, Subramanian A, Nirantharakumar K, Yiangou A, Gokhale KM, Mollan SP, et al. Association Between Idiopathic Intracranial Hypertension and Risk of Cardiovascular Diseases in Women in the United Kingdom. JAMA Neurol. 2019;76(9):1088-1098. 10.1001/jamaneurol.2019.1812.

20. Subramaniam S, Fletcher WA. Obesity and Weight Loss in Idiopathic Intracranial Hypertension: A Narrative Review. J Neuroophthalmol. 2017;37(2):197-205. 10.1097/WNO.0000000000000448.

21. Schwartz R, Kliper E, Stern N, Dotan G, Berliner S, Kesler A. The obesity pattern of idiopathic intracranial hypertension in men. Graefes Arch Clin Exp Ophthalmol. 2013;251(11):2643-6. doi: 10.1007/s00417-013-2420-6.

22. Kalyvas A, Neromyliotis E, Koutsarnakis C, Komaitis S, Drosos E, Skandalakis GP, et al. A systematic review of surgical treatments of idiopathic 
Annals of International Medical and Dental Research

E-ISSN: 2395-2822 | P-ISSN: 2395-2814

Vol-8, Issue-1 | January-February 2022

DOI: $10.53339 /$ aimdr.2022.8.1.42

Page no- 333-340 | Section- Research Article (Neuro Surgery)

intracranial hypertension (IIH). Neurosurg Rev. 2021;44(2):773-792. doi: 10.1007/s10143-020-01288-1.

23. Gilbert AL, Chwalisz B, Mallery R. Complications of Optic Nerve Sheath Fenestration as a Treatment for Idiopathic Intracranial Hypertension. Semin Ophthalmol. 2018;33(1):36-41. doi: 10.1080/08820538.2017.1353810.
24. Redfern MS, Yardley L, Bronstein AM. Visual influences on balance. J Anxiety Disord. 2001;15(12):81-94. doi: 10.1016/s0887-6185(00)00043-8.

Source of Support: Nil, Conflict of Interest: None declared 